\title{
Superoxidizement of metallic oxides by means of the ferridcyanide of potassium
}

\section{Boudault}

To cite this article: M. Boudault (1845) Superoxidizement of metallic oxides by means of the ferridcyanide of potassium, Philosophical Magazine Series 3, 27:180, 308-310, DOI: 10.1080/14786444508645284

To link to this article: http://dx.doi.org/10.1080/14786444508645284

曲 Published online: 30 Apr 2009.

Submit your article to this journal $₫$

Џll Article views: 3

Q View related articles $๘$ 
The author concluded that the decomposition of ferridcyanide into ferrocyanide, would afford cyanogen which would act as if it were free; and he found that when he heatec oxide of lead in a mixture of ferridcyanide and potash, he procured binoxide of lead, and the solution contained ferrocyanide of potassium only. Having thus proved that the ferridcyanide might be substituted for cyanogen as an oxidizing agent, experiments were performed on the superoxidizement of various oxides.-Journ. de Pharm. et de Ch., Juin 1845.

\section{SUPEROXIDIZEMENT OF METALLIC OXIDES BY MEANS OF THE FERRIDCYANIDE OF POTASSIUM. BY M. BOUdAULT.}

The author remarks, that metallic oxides in general have a tendency to pass to a higher degree of oxidizement; and some of them undergo it with great readiness, under the oxidizing influence of cyanogen, either at common temperatures or when boiling, according as the oxide is more or less superoxidizable.

Oxide of Manganese.- When protoxide of manganese, which has been precipitated without the contact of air, or a salt containing this oxide, is added to a mixed solution of cold ferridcyanide of potassium and potash, there are immediately obtained peroxide of manganese and ferrocyanide of potassium : with a large quantity of potash, crystallized peroxide of manganese was formed. If, instead of adding an excess of ferridcyanide, an excess of a salt of manganese be employed with a large quantity of potash, a reddish-brown precipitate may be obtained, which is probably the manganoso-manganic oxide.

Oxide of Nickel and Oxide of Cobalt.-The protoxide of nickel, when added to an alkaline solution of the red salt, does not appear to be superoxidized; and if it be boiled for some time decomposition occurs unconnected with oxidizement.

The same is the case with oxide of cobalt; there occurs, nevertheless, a moment in which the oxide of cobalt seems to be superoxidized, but it is probably reduced by the ferrocyanide which is formed.

Oxide of Lead.-The superoxidation of lead is the most marked of any oxide; a salt of oxide of lead, or the oxide itself, when dissolved in potash, is converted into binoxide, and almost always precipitated in the crystalline state; this latter fact, however, appears to depend upon the quantity of potash employed. On some occasions the author obtained minium by employing excess of the salt of lead, and heating the liquor but slightly.

Oxide of Copper.-The ferridcyanide of copper, or the oxide, are superoxidized by the mixed solution of ferridcyanide of potassium and potash; there are obtained a black precipitate, and ferrocyanide as usual.

Oxide of Tin.-The salts of protoxide of tin effect a reduction of the ferridcyanide, which indicates superoxidizement; but the author could not ascertain the nature of the oxide which is precipitated. 
This oxide may probably be the stannate of protoxide of tin, discovered by $\mathrm{M}$. Fremy ( $\left.\mathrm{SnO}, \mathrm{Sn}^{3} \mathrm{O}^{6}\right)$.

Oxide of Chromium, when dissolved in potash and heated with the ferridcyanide to the boiling-point, is converted into chromate of potash; and if sufficient oxide be used, all the ferridcyanide is reduced to ferrocyanide; this is evidently an example of very energetic oxidation, for hitherto chromate of potash has not been procured in the moist way.

Oxides of Gold and Silver are not superoxidized by the ferridcyanide; in a cold solution no effect is produced, but at a temperature near that of ebullition, peroxide of iron is precipitated; and the solution contains ferrocyanide of potassium, and cyanide of gold dissolved in the cyanide of potassium.

The salts of silver exhibit similar phænomena, viz. the formation of ferrocyanide, precipitation of peroxide of iron; and the solution contains ferrocyanide of potassium, which being precipitated by alcohol, cyanide of silver and cyanide of potassium were obtained. These facts are not included in simple oxidizement, they are true decompositions.

Sulphur may also be oxidized by this same influence; it becomes sulphuric acid.

Acids and Salts.-Certain mineral acids may be oxidized, whether free or combined; phosphorous acid and the soluble hypophosphites are converted into phosphates; sulphurous acid yields sulphuric acid, the sulphites are converted into sulphates. Oxalic acid, and oxalates added to the alkaline solution, yield carbonates almost instantaneously.

M. Boudault gives the following explanation of the phænomena which he has described :-the ferridcyanide of potassium is considered by him as a double salt, that is to say, as a compound of percyanide of iron and cyanide of potassium; this percyanide of iron, therefore, does not exist in a free state, and being a very unstable salt, it is retained in the red prussiate by the cyanide of potassium. As soon as a reaction takes place in the presence of this salt, it has a tendency to be decomposed, and the author gives the following as explanatory of his views :-

$$
\mathrm{Cy}^{3} \mathrm{Fe}^{2}+\mathrm{Cy}^{3} \mathrm{~K}^{3}=\mathrm{Cy}^{2} \mathrm{Fe}^{2}+\mathrm{Cy}^{3} \mathrm{~K}^{3}+\mathrm{Cy} \text {. }
$$

On adding potash and oxide of lead, we have

$$
\begin{aligned}
& \mathrm{Cy}^{2} \mathrm{Fe}^{2} \mathrm{Cy}^{3} \mathrm{~K}^{3}+\mathrm{Cy}+\mathrm{KO}+\mathrm{PbO} \\
= & \mathrm{Cy}^{2} \mathrm{Fe}^{2} \mathrm{Cy}^{3} \mathrm{~K}^{3}+\mathrm{CyK}+\mathrm{PbO}^{2} \\
= & 2 \mathrm{CyFe} \mathrm{Cy} \mathrm{Ky}^{2}+\mathrm{PbO}^{2} .
\end{aligned}
$$

By this formula we find two equivalents of ferrocyanide of potassium and binoxide of lead, which is what we obtain by the reaction which it explains.

The author considers the ferridcyanide of potassium, under the circumstances described, as ferrocyanide, minus potassium, and consequently as possessing an equivalent of free cyanogen, capable of replacing cyanogen. It is therefore demonstrated, M. Boudault oncludes, that cyanogen possesses the additional analogy with chlo- 
rine, iodine and bromine, of being like them an energetic oxidizer. -Journ. de Pharm. et de Ch., Juin 1845.

\section{PHOSPHORIC ACID FOUND IN ALMOST ALL ROCKS*.}

The following extracts from a lecture by Dr. R. D. Thomson in the forthcoming number of the Quarterly Agricultural Journal of Scotland, taken in conjunction with the paper printed in the Philosophical Magazine on the Inorganic Constituents of Lichens, render it obvious that few rocks will be found destitute of phosphoric acidt.

Greywacke Soil.-By explaining geologically the dependence of the soil upon rocks, and tracing the production of various soils from their respective rocks, not only may much interest, but much instruction be derived in the chemical studies of the agriculturist. During the last winter many careful analyses of rocks have been made. These I do not intend to describe at present; but, as an example of the importance of such analyses, I may notice those of the greywacke and the superimposed soil at Balkerr in Wigtonshire. The experiments were conducted by my pupil, Mr. James M'Bryde, under my immediate direction. The analyses of the rock and soil are placed in parallel columns for the sake of comparison. Specific gravity of the rock $2 \cdot 76$.

\begin{tabular}{|c|c|c|c|c|c|}
\hline Decomposed soil. & Soil. & Greywacke. & $\begin{array}{l}\text { Partially undecom. } \\
\text { posed soil. }\end{array}$ & Soil. & Greywacke. \\
\hline $\left.\begin{array}{c}\text { Fibre ................. } \\
\text { Organic matter and } \\
\text { some water of un- } \\
\text { Phosphate of iron .... } \\
\text { Peroxide of iron...... } \\
\text { Carbonate of lime ... } \\
\text { Magnesia............... } \\
\text { Chloride of sodium } \\
\text { Sulphate of lime... }\end{array}\right\}$ & $\begin{array}{r}1 \cdot 01 \\
12.51 \\
2 \cdot 49 \\
7 \cdot 60 \\
\cdot 74 \\
1 \cdot 72 \\
0.05\end{array}$ & $\begin{array}{r}0 \cdot 94 \\
9 \cdot 94 \\
\\
\text { trace. }\end{array}$ & 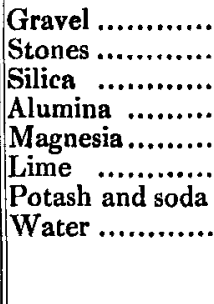 & $\begin{array}{r}6 \cdot 39 \\
19 \cdot 16 \\
38.79 \\
8 \cdot 30 \\
0 \cdot 69 \\
0 \cdot 55 \\
\cdots \ldots \ldots . .\end{array}$ & $\begin{array}{r}72 \cdot 18 \\
11 \cdot 68 \\
2 \cdot 30 \\
0.96 \\
0.95 \\
2 \cdot 40\end{array}$ \\
\hline
\end{tabular}

The important fact that phosphoric acid is contained in greywacke is demonstrated by this analysis. In another examination we found a somewhat larger amount, and the variation may be considerable in different localities. A comparison of the preceding columns enables us to deduce the effects of cultivation. It is obvious that phosphoric acid and carbonate of lime have been added artificially. Phosphoric acid has been long known to exist in volcanic rocks (Boussingault's Economie Rurale, i. 561), and the fact has been confirmed by Mr. Fownes, but I am not aware that its occurrence in primary rocks was pointed out until the experiments made here in 1843, upon lichens, demonstrated the fact $\ddagger$. I have since analysed all the primary rocks,

- Communicated by Dr. Thomson.

+ See also the very complete researches of Mr. Sullivan on this subject in our last number. -EDs.

I See the Journal of Agriculture for January 1845, No. 8. 